Revista Eletrônica do Mestrado

Profissional em Administração da UnP

\title{
edunp
}

V. 10, N. 3, 2018

ISSN 1984-4204

https://repositorio.unp.br/index.php/raunp

https://doi.org/10.21714/raunp.v10i3.1838

\section{Ferramentas e informações gerenciais em micro e pequenas empresas}

\section{Tools and management information among micro and small companies}

\author{
Antônio André Cunha Callado ${ }^{a}$, Wilton Alexandre de Melo ${ }^{b}$ \\ ${ }^{a}$ Doutor em Administração. Universidade Federal Rural de Pernambuco (UFRPE). Programa de Pós-Graduação em Controladoria \\ (PPGC). andrecallado@yahoo.com.br

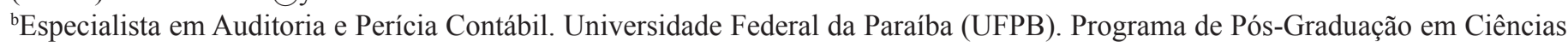 \\ Contábeis (PPGCC). wiltoncongo@gmail.com
}

\begin{abstract}
Resumo
Este trabalho teve por objetivo verificar como funciona a utilização das ferramentas e informações gerenciais nos micro e pequenos empreendimentos atuantes no Cariri Ocidental da Paraíba. Com a finalidade de se alcançar o respectivo objetivo, foi selecionada uma amostra com 32 micro e pequenas empresas escolhidas por acessibilidade e provenientes das cidades de Congo, Sumé, Serra Branca e Ouro Velho. Foi aplicado um questionário contendo 25 questões subjetivas e objetivas. A metodologia utilizada foi de natureza descritiva, exploratória, com a técnica de survey e de abordagem qualitativa. Para apresentação dos dados se utilizou tanto da descrição, como da apresentação das frequências e médias através de tabelas, quando pertinentes. A análise seguiu com base nas correlações entre as questões e na percepção dos respondentes quanto ao conteúdo proposto. Os principais resultados apontam por uma utilização acentuada por parte dos entrevistados, $53,1 \%$ da amostra, sendo que as ferramentas de cunho fiscal são as mais expressivas e as contábeis são as menos utilizadas. A contabilidade é percebida como aliada, mas pouco utilizada pelas empresas analisadas uma vez que os empresários em sua maioria tomam decisões e gerenciam seus negócios com base em experiências passadas.
\end{abstract}

Palavras-chave: Informações Gerenciais; Ferramentas Gerenciais; Micro e Pequenas Empresas.

\begin{abstract}
The objective of this paper was to verify how the use of tools and management information in micro and small companies operating in the Western Cariri of Paraíba. In order to reach this objective, a survey considering a sample of 32 micro and small companies chosen for accessibility and coming from the cities of Congo, Sumé, Serra Branca and Ouro Velho was selected. A questionnaire containing 25 subjective and objective questions was applied. The methodology used was descriptive, exploratory, and qualitative approach. For the presentation of the data, both the description and the presentation of the frequencies and averages were used through tables, when pertinent. The analysis followed based on the correlations between the questions and the respondents' perception of the proposed content. The main results point to a marked use by the interviewees, 53.1\% of the sample, with the tax tools being the most expressive and the accounting are the least used. Accounting is perceived as ally but little used by the companies analyzed since entrepreneurs mostly make decisions and manage their business based on past experiences.
\end{abstract}

Keywords: Management Information; Management Tools; Micro and Small Business. 


\section{Introdução}

O cenário atual tem se revelado um desafio para empreendedores e empreendimentos onde a competitividade tornou-se apenas um dos diversos fatores a ser considerado no tocante à tomada de decisão.

De acordo com o Serviço Brasileiro de Apoio às Micro e Pequenas Empresas - Sebrae (2015), além da própria competitividade, algo inerente a quase todo empreendimento, a crise iniciada em 2008 pode frear de maneira significativa o avanço dos pequenos negócios.

Esse impacto, bem como a preocupação com seus reflexos, se justifica pelo fato dessas empresas serem, atualmente, responsáveis pela geração de $52 \%$ dos empregos formais no Brasil e por $27 \%$ do Produto Interno Bruto (PIB). Diante desse panorama, o cenário de retração na economia deve fazer com que essa realidade mude e produza efeitos negativos no decorrer do tempo (Sebrae, 2015).

Porém, esse não é um único fator significativo que deve ser considerado pelos empreendimentos. Como destacado inicialmente, a competitividade ainda é fator relevante devido principalmente aos avanços tecnológicos e de informação (Bomfim, Teixeira \& Callado, 2013).

Manter e desenvolver formas de gerenciamento a partir da identificação das principais dificuldades encontradas torna-se, atualmente, fator decisivo na continuidade ou não do negócio (Callado, Callado \& Silva, 2011). Panucci Filho e Almeida (2010) enfatizam que para as empresas em crescimento alcançarem a sua maturidade, em termos de gerenciamento e tomada de decisão, torna-se essencial à utilização da contabilidade no processo de gestão, considerada como importante instrumento de controle.

Diante disso, surge o problema da pesquisa: como se dá a utilização de ferramentas e informações gerenciais nos micro e pequenos empreendimentos atuantes no Cariri Ocidental da Paraíba?

O objetivo desta pesquisa consiste em verificar como se dá a utilização de ferramentas e informações gerenciais nos micro e pequenos empreendimentos atuantes no Cariri Ocidental da Paraíba. Quanto aos objetivos específicos: (a) identificar as principais ferramentas gerenciais utilizadas; (b) demonstrar o nível de utilização da Contabilidade Gerencial e suas ferramentas e informações na tomada de decisão; e (c) apresentar os principais fatores que motivam ou impedem a implantação e utilização das ferramentas gerenciais dentro das micro e pequenas empresas.

Esta pesquisa se justifica por contribuir para a ampliação do conhecimento na área gerencial, sobretudo dentro dos micro e pequenos empreendimentos, a partir do momento em que volta sua atenção para este percentual de agentes cumprindo, assim, um papel importante, transformando ou pelo menos possibilitando a geração de conhecimento que auxilie na mudança da realidade.

\section{Contabilidade e ferramentas gerenciais}

Dentro dos empreendimentos existem diversas formas que podem ser utilizadas quando se busca um melhor gerenciamento das atividades. As informações predominantemente de cunho interno auxiliam o gestor no processo decisório proporcionando melhores resultados.

$\mathrm{O}$ ambiente em que as empresas estão inseridas pode ser considerado hostil, e responder adequadamente, assim como também assegurar a manutenção do desempenho da empresa, é tarefa complexa, dado que as mudanças ocorrem de maneira rápida e constante (Morais, Coelho \& Holanda, 2014).

Iudícibus, Marion e Faria (2017) apresentaram um panorama onde diversas empresas, principalmente as pequenas, têm encerrado suas atividades ou enfrentam sérios problemas de sobrevivência, decorrentes de 
dificuldades na gestão, uma vez que utilizam a contabilidade apenas para atender as exigências fiscais. Uma das premissas basilares da informação contábil é contribuir para a tomada de decisão, de modo que as melhores práticas sejam adotadas pelos gestores. Essas informações são necessárias para todo tipo de organização (Santos, Dorow \& Beuren, 2016).

A Contabilidade Gerencial produz informações que permitirão uma tomada de decisão precisa e em conformidade com o objetivo empresarial, uma vez que a continuidade dos empreendimentos está associada aos resultados positivos que forem gerados (Moura, Pereira \& Rech, 2016).

Contextualizando a Contabilidade Gerencial como ferramenta importante no processo de gestão das informações, em especial nas Micro e Pequenas Empresas (MPE), Prakash (2013) enfatiza que ela disponibiliza informações relevantes para a formulação de estratégias de negócios, atividades de planejamento e controle, tomada de decisão, utilização eficiente dos recursos e otimização do desempenho e criação de valor da empresa. Santos, Dorow e Beuren (2016) consideram que as informações contábeis são necessárias para a tomada de decisão em todos os tipos de organizações, sendo que nos pequenos negócios a informação se torna vital para o processo de continuidade.

Sendo internos ou externos, os tomadores de decisão se beneficiam a partir do momento em que a contabilidade, no fiel cumprimento do seu papel, lhes fornece informações que os auxiliem a planejar e a controlar as operações das organizações (Horngrenet al., 2008).

Quando se trata de tomada de decisão, as MPE se apresentam em desvantagem dada à incipiência de estudos, bem como de aspectos práticos na geração de informação gerencial.

Diante da ausência de informações para a tomada de decisão ou na existência dessas, de sua pouca utilização, Sales, Barros e Pereira (2011) descrevem que as pequenas empresas têm enfrentado dificuldades na gestão dos negócios, levando assim, à mortalidade precoce, fato este corroborado pelo SEBRAE (2015), onde estas possuem uma expectativa de "vida" média de dois anos.

No entanto, Santos, Dorow e Beuren (2016) assumem que tais dificuldades poderiam ser minimizadas se houvesse uma maior utilização de instrumentos gerenciais assim como são utilizados nas médias e grandes. Carmo, Santos e Lima (2013) objetivaram conhecer e analisar os artefatos de custos utilizados no processo de gestão de 50 MPE dos setores de comércio, serviços, indústria e construção civil da cidade de Uberlândia, em Minas Gerais. Em síntese, o estudo evidenciou que 56\% das MPE analisadas utilizam algum tipo de planejamento no seu processo de gestão, e, com relação específica a custos, foi constatado que $82 \%$ das empresas analisadas parecem não conhecer, sequer, as metodologias de custeio tradicionais.

Outros estudos apontam a importância de ferramentas gerenciais dentro dos empreendimentos, o que acarreta também uma nova postura por parte do profissional de contabilidade.

Teixeira et al. (2011) buscaram evidenciar se empresas do estado do Espírito Santo utilizavam ferramentas modernas de Contabilidade Gerencial. Como resultado foi identificado que as empresas utilizavam tanto ferramentas tradicionais como ferramentas modernas da Contabilidade Gerencial.

Todo esse processo contribui para um melhor gerenciamento empresarial a partir da melhor escolha de ferramentas, uma vez que, estes tipos empresariais possuem significativa importância na geração de riqueza em renda.

Este fato é corroborado pelo trabalho de Cabral, Silva e Magalhães (2012) onde na demonstração do panorama das Micro e Pequenas Empresas no município de Pouso Alegre/MG, as mesmas representavam 99\% desses empreendimentos existentes gerando um aumento significativo de emprego e renda entre 1985 e 2010. 
Em um trabalho mais recente, Santos et al. (2017) objetivaram analisar os artefatos gerenciais utilizados na tomada de decisão pelos gestores dos Food Trucks na cidade de Natal/RN com base no modelo proposto pelo International Federation of Accountants (IFAC). Dentre os principais resultados, percebe-se uma limitada utilização dos artefatos gerenciais por estes tipos empresariais.

Beuren e Rengel (2012) averiguaram o uso dos atributos da Contabilidade Gerencial, conforme proposto por Moores e Yuen (2001) nas empresas do segmento industrial de máquinas, aparelhos e materiais elétricos do Estado de Santa Catarina. Os resultados demonstraram que os respectivos atributos são utilizados pelas empresas.

Moura, Pereira e Rech (2016) verificaram o uso de ferramentas e informações gerenciais por produtores rurais, identificando os fatores que os motivam a utilizar estas ferramentas no direcionamento e planejamento de seu negócio. Os resultados evidenciaram que os produtores rurais, de um modo geral, utilizam algumas informações gerenciais informais para a manutenção ou controle de sua produção. Também se detectou uma limitação em adotar a contabilidade e suas informações como ferramenta gerencial e de controle.

Ainda outros estudos ajudam a corroborar a importância dessas ferramentas no processo decisório se utilizadas de maneira eficiente e com auxilio da contabilidade.

O estudo de Santos et al. (2009), concluíram em sua pesquisa que há necessidade de mudança na relação das micro e pequenas empresas com a contabilidade e o aperfeiçoamento dos serviços oferecidos pelos profissionais das empresas de serviços contábeis.

Por sua vez Silva et al. (2010), verificaram que na maioria das MPE, os relatórios que são disponibilizados são os mais tradicionais e menos sofisticados, bem como a que a maioria dos gestores não se utiliza da contabilidade para acompanhar metas, medir desempenhos e avaliar impactos financeiros de suas decisões, deixando assim de fazer uso gerencial dos relatórios.

A pesquisa de Moreira et al. (2013) enfatiza que a contabilidade é vista como mera executora das obrigações fiscais e trabalhistas, fazendo com que os gestores não percebam a importância da informação contábil. Constatou-se ainda que os gestores com maior nível de formação compreendem a relevância da contabilidade, mas não manteriam o contador caso houvesse uma simplificação no recolhimento dos tributos.

Porfim a pesquisa de Pianovski e Barella (2016) verificou que os gestores dos pequenos empreendimentos possuem pouco conhecimento sobre as principais ferramentas e sua importância na gestão do negócio.

A partir de diversas fontes, pode-se perceber que a Contabilidade Gerencial e suas ferramentas possuem cabal importância tanto dentro de médias e grandes empresas, como também dentro do contexto das pequenas empresas.

\section{Procedimentos metodológicos}

Com relação aos objetivos, essa pesquisa se classifica como descritiva e exploratória. No que se refere a abordagem do problema a mesma é quali-quantitativa. A técnica utilizada para coleta de dados foi um survey (Marconi \& Lakatos, 2005; Clemente, 2007; Gil, 1999; Collins \& Hussey, 2005; Beuren, 2012; Richardson, 1999).

A pesquisa descritiva, de acordo com Gil (2008), busca descrever de maneira analítica as características de determinada população ou de determinado fenômeno, sendo uma de suas peculiaridades a utilização de peças padronizadas para coleta de dados como um questionário e a observação sistemática. 
A pesquisa exploratória tem por finalidade proporcionar maior familiaridade com o problema em análise. Seria uma forma de tornar mais explícita a temática em questão, onde pode envolver levantamento bibliográfico prévio, bem como entrevistas com pesquisadores experientes (Gil, 2008; Gerhardt \& Silveira, 2009).

O Survey ou levantamento se desenvolve a partir da interação entre pesquisador e pesquisados de modo direto, onde a partir disso se proporciona uma maior familiaridade com o objeto de estudo (Gil, 2008).

$\mathrm{O}$ ambiente de pesquisa foi a Microrregião do Cariri Ocidental paraibano que pertence a Mesorregião da Borborema e possui 17 municípios, apresentados no Quadro 1. Objetivamente, de acordo com IBGE (2017), a respectiva região possui uma estimativa populacional de 128.326 habitantes, e o seu PIB apurado no período foi de R\$237.147.763,00.

Municípios da Microrregião do Cariri Ocidental Paraibano

\begin{tabular}{|c|c|}
\hline Município & Município \\
\hline Amparo & Prata \\
\hline Assunção & São Joao do Tigre \\
\hline Camalaú & São Jose dos Cordeiros \\
\hline Congo & S. S. do Umbuzeiro \\
\hline Coxixola & Serra Branca \\
\hline Livramento & Sumé \\
\hline Monteiro & Taperoá \\
\hline Ouro Velho & Zabelê \\
\hline Parari & \\
\hline
\end{tabular}

Quadro 1

Fonte: IBGE, 2017

Os sujeitos da pesquisa foram empresários atuantes no Cariri Ocidental paraibano. A amostra se deu por acessibilidade e foi formada a partir de um levantamento nas organizações contábeis da região. Esses indivíduos respondentes deveriam estar vinculados a empresas abrangidas pela Lei Complementar $n^{\circ}$ 123/2006, no que se refere ao faturamento e no Ibge (2015) no que se refere ao número de empregados. Para fins deste estudo, não foi considerado o microempreendedor individual, previsto na Lei Complementar $n^{\circ}$ 128/2008, uma vez que, de acordo com a respectiva lei, uma contabilidade mais formalizada é dispensada.

Como meio de coletar os dados dessas empresas e responder ao problema de pesquisa, foi elaborado um questionário contendo 25 questões objetivas (múltipla escolha) e subjetivas divididas nas seguintes partes: (a) características do respondente; (b) características das empresas; (c) informações e ferramentas gerenciais utilizadas. O mesmo foi baseado a partir de leituras de diversos estudos que trataram da temática, Martins (2014), Araújo et al. (2015), Moura, Pereira e Rech (2016), Stacke e Feil (2017), Santos et al. (2017).

Após a aplicação do pré-teste e tendo considerado as correções e efetuado os ajustes sugeridos e pertinentes por parte dos entrevistados escolhidos, o mesmo foi aplicado in loco nos municípios constantes no Quadro 1, sendo que por falta de informação acerca de um universo, se aplicou aleatoriamente 10 questionários em cada município escolhido. Fixou-se um prazo inicial para o retorno dos questionários respondidos de uma semana, de modo que as análises pudessem ser efetuadas em seguida ao recolhimento. 
Como retorno dos questionários respondidos se obteve uma amostra de 32 micro e pequenas empresas. Os respondentes são oriundos dos municípios de Congo (13), Sumé (8), Serra Branca (10) e Ouro Velho (1). Tendo efetuado diversos contatos com os demais onde os questionários foram deixados, não se obteve resposta, sendo, portanto, a amostra formada pelos que responderam.

Para análise foram utilizadas medidas estatísticas descritivas (frequências e médias), cujos resultados estão apresentados em tabelas. Com relação à terceira parte que trata das ferramentas e informações gerenciais, as mesmas tiveram análises tanto descritivas como algumas transcrições de respostas provenientes das questões subjetivas. Nessa parte não se buscou a redação literal das respostas dos entrevistados e sim o entendimento do que foi apresentado como justificativa para algumas das questões abordadas, ou seja, a análise descritiva de questões objetivas, de certo modo, foi justificada pelas respostas subjetivas.

Como limitação de análises, na tabulação dos dados foi identificada que algumas questões, majoritariamente subjetivas foram deixadas em branco, sendo, em alguns momentos, efetuadas as análises com base nas questões efetivamente respondidas, o que em alguns casos, as frequências diferem de outras questões analisadas. Os resultados são apresentados no tópico seguinte.

\section{Análise e discussão dos resultados}

\subsection{Características dos respondentes}

A tabela 1 sintetiza de maneira objetiva as características dos respondentes da pesquisa no que se refere ao cargo ocupado na empresa, ao tempo de atuação nesse cargo, sua faixa etária, escolaridade e área de formação.

\section{Tabela 01}

Características dos respondentes

\begin{tabular}{|c|c|c|c|c|c|c|c|}
\hline \multicolumn{8}{|c|}{ Cargo na Empresa } \\
\hline \multicolumn{3}{|c|}{ Gerente } & \multicolumn{2}{|c|}{ Administrador } & \multicolumn{2}{|l|}{ Contador } & Outro \\
\hline \multicolumn{3}{|c|}{11} & \multicolumn{2}{|c|}{20} & \multicolumn{2}{|l|}{0} & 1 \\
\hline \multicolumn{3}{|c|}{$34,4 \%$} & \multicolumn{2}{|c|}{$62,5 \%$} & \multicolumn{2}{|l|}{$0 \%$} & $3,1 \%$ \\
\hline \multicolumn{8}{|c|}{ Tempo de Atuação (em anos) } \\
\hline 1 a 5 & \multicolumn{2}{|c|}{6 a 10} & 11 a 15 & 16 a 20 & \multicolumn{2}{|l|}{21 a 25} & Acima de 25 anos \\
\hline 8 & \multicolumn{2}{|c|}{6} & 7 & 4 & \multicolumn{2}{|l|}{2} & 5 \\
\hline $25 \%$ & \multicolumn{2}{|c|}{$18,8 \%$} & $21,9 \%$ & $12,5 \%$ & \multicolumn{2}{|l|}{$6,3 \%$} & $15,6 \%$ \\
\hline \multicolumn{8}{|c|}{ Faixa Etária (em anos) } \\
\hline Menos de 20 & \multicolumn{2}{|c|}{21 e 25} & 26 e 30 & 31 e 35 & \multicolumn{2}{|l|}{36 e 40} & Acima de 40 \\
\hline 0 & \multicolumn{2}{|c|}{3} & 3 & 3 & \multicolumn{2}{|l|}{10} & 12 \\
\hline $0 \%$ & \multicolumn{2}{|c|}{$9,4 \%$} & $9,4 \%$ & $9,4 \%$ & \multicolumn{2}{|l|}{$31,3 \%$} & $37,5 \%$ \\
\hline \multicolumn{8}{|c|}{ Escolaridade } \\
\hline Fund Inc. & Fund.Comp. & Med. Inc. & Med. Comp. & Sup. Inc. & Sup. Comp. & Tec. & PGD \\
\hline 4 & 1 & 1 & 16 & 2 & 7 & 0 & 1 \\
\hline $12,5 \%$ & $3,1 \%$ & $3,1 \%$ & $50 \%$ & $6,3 \%$ & $21,9 \%$ & $0 \%$ & $3,1 \%$ \\
\hline
\end{tabular}

Fonte: Dados de pesquisa, 2017

\subsection{Características das empresas}

Nessa parte são apresentadas as principais características dos estabelecimentos pesquisados a partir dos dados da Tabela 2. 
Tabela 2

Características das Empresas

\begin{tabular}{|c|c|c|c|}
\hline \multicolumn{4}{|c|}{ A empresa é: } \\
\hline Estabelecimento único & \multicolumn{2}{|c|}{ Pertence a um grupo empresarial } & Outro \\
\hline 31 & \multicolumn{2}{|c|}{1} & 0 \\
\hline $96,9 \%$ & \multicolumn{2}{|c|}{$3,1 \%$} & $0 \%$ \\
\hline \multicolumn{4}{|c|}{ Ramo de atividade } \\
\hline Comércio & Indústria & Serviços & Outros \\
\hline 28 & 0 & 2 & 2 \\
\hline $87,5 \%$ & $0 \%$ & $6,3 \%$ & $6,3 \%$ \\
\hline \multicolumn{4}{|c|}{ Tempo de funcionamento } \\
\hline Menos de 5 anos & 5 a 15 anos & 16 a 25 anos & Acima de 25 anos \\
\hline 7 & 12 & 8 & 5 \\
\hline $21,9 \%$ & $37,5 \%$ & $25 \%$ & $15,6 \%$ \\
\hline
\end{tabular}

Fonte: Dados de Pesquisa, 2017.

No que se refere ao tempo de funcionamento, as empresas não apresentaram um padrão único, ficando uma pequena maioria compreendidas entre 5 e 15 anos. O que se pode inferir desses dados e tomando por base a análise conjunta daqueles empresários que atuam a mais de 5 anos (ver Tabela 1), é que os mesmos possuem relativa experiência no negócio, o que destoa da realidade apresentada pelo Sebrae (2015) onde apresenta os 2 primeiros anos de funcionamento como sendo críticos sendo nesse período onde ocorre o maior número de mortalidade precoce dessas empresas.

Com relação ao ramo de atividade, os que responderam a alternativa "outros", são de empresas que possuem em sua razão social uma dupla função, ou seja, exercem o comércio, mas também possuem a função de prestação de serviços.

\subsection{Informações e ferramentas gerenciais}

No que se refere às informações e ferramentas gerenciais utilizadas pelas empresas no processo de tomada de decisão, o que se buscou foi identificar não somente se os mesmos utilizam ou não tais ferramentas, mas também se as conhecem e os motivos que os impedem de utilizá-las.

Incialmente destaca-se que em $96,9 \%$ das empresas pesquisadas o proprietário participa da gestão de maneira direta. Nos 3,1\% em que o proprietário não atua na gestão, o mesmo alegou que o "companheiro" é quem exerce a gerência e administração do negócio.

Em 93,8\% dos estabelecimentos, os serviços de contabilidade são prestados por profissional de contabilidade externo a empresa em que as informações são enviadas a esse profissional que por sua vez prepara os relatórios e os entrega a empresa demandante. Apenas 6,2\% responderam que a contabilidade é feita de maneira interna, com profissional contratado para este fim.

Dessa relação com a contabilidade se questionou também se o empresário considera que a contabilidade prestada auxilia no processo de gestão da entidade. Como resposta, observou-se que 87,5\% dos que responderam a pesquisa, consideram que "sim", a contabilidade é relevante e auxilia no processo de gestão. Outros $12,5 \%$ responderam que "não", a contabilidade não auxilia nesse processo, sendo que os principais motivos apresentados foram: "a contabilidade só atua com finalidade de atender as exigências fiscais", "não há necessidade de contabilidade atuando no auxílio à gestão" e "não houve propostas por parte do contador que 
se referisse a esse tipo de serviço".

Para os que responderam que a contabilidade auxilia nesse processo de gestão não se pode afirmar que a mesma é presente e atuante dentro dos empreendimentos, já que quando se trata da percepção da sua utilidade no processo de gestão, os resultados apresentados tiveram uma ligeira queda para $65,6 \%$ sendo que outros fatores que explicam essa queda foram justificados como: "a contabilidade atua quando necessário (12,5\%)", "a contabilidade atua quando solicitada (15,6\%)" e "a contabilidade não atua nesse processo, pois não há necessidade (6,3\%)". Estes fatores mesmo analisados em conjunto não sobrepõem aos que consideraram que a contabilidade atua e é importante no processo de gestão e tomada de decisão, porém é um percentual a se considerar, uma lacuna a se cobrir.

Outra variável que se propôs e que corrobora outras analisadas no parágrafo imediatamente anterior e ao mesmo tempo destoa das mesmas, é: como os empresários avaliam a participação da contabilidade no processo decisório. Apenas 25\% consideraram que a mesma é "eficaz" ficando os demais percentuais distribuídos entre: relativamente eficaz, com uma participação além das questões fiscais ocorrendo quando solicitada (50\%), pouco eficaz, participando apenas das questões fiscais $(12,5 \%)$ e ineficaz $(12,5 \%)$, ou seja, não participa do processo de gestão.

Comparando os resultados das variáveis que trataram da temática se a contabilidade auxilia no processo de gestão, com os apresentados pela variável em que se procurou a percepção da eficácia ou não nesse processo, se percebe que o elevado nível de satisfação apresentado naquelas possui relação com os serviços prestados pela contabilidade quando solicitados ou quando prestados, e não necessariamente uma participação ativa da contabilidade no processo de gestão e tomada de decisão da empresa.

Questionou-se com base em uma lista com 23 ferramentas gerencias, quais eram utilizadas na gestão da empresa. Por questão de extensão, será utilizada a frequência média para fins de análise, onde se considerou o total dos que responderam "sim" a utilização das 23 ferramentas apresentadas, os que responderam que "as vezes" utilizam na gestão, os que responderam que "não" utilizam as respectivas ferramentas e os que “desconhecem” a ferramenta e portanto não a utilizam no processo de gestão e tomada de decisão.

Como resultados se tem que dos 32 respondentes, cerca de 17 , ou 53,1\%, utilizam as ferramentas apresentadas sendo que não na mesma frequência e intensidade, tendo maior frequência de utilização por exemplo: "caixa gerado no mês", "fluxo de caixa", "lucro do mês", "rotinas trabalhistas", "rotinas fiscais e tributárias", "saldos de contas", contas a pagar", contas a receber" e "formação de preço de venda". Em detrimento as apresentadas anteriormente, as informações eminentemente contábeis que tiveram baixo nível de utilização foram: "depreciações de equipamentos", "ponto de equilíbrio", "Balanço patrimonial", "Demonstração de Resultado" e "Balancete de verificação", sendo estas ultimas as que obtiveram maior nível de não utilização ou desconhecimento por parte do empresário.

Os resultados apresentados são corroborados quando se trata dos motivos para utilização e não utilização das respectivas ferramentas, apresentados nas Tabelas 3 e 4 abaixo.

Tabela 3

Principais motivos de não utilização das ferramentas gerenciais

\begin{tabular}{ccccc}
\hline Não conheço & $\begin{array}{c}\text { Não conheço e o con- } \\
\text { tador não auxilia }\end{array}$ & $\begin{array}{c}\text { Conheço parcialmente, } \\
\text { mas sou inseguro }\end{array}$ & $\begin{array}{c}\text { Conheço mas não } \\
\text { considero útil }\end{array}$ & Outros \\
\hline 12 & 3 & 5 & 9 & 3 \\
\hline $37,5 \%$ & $9,4 \%$ & $15,6 \%$ & $28,1 \%$ & $9,4 \%$ \\
\hline
\end{tabular}

Fonte: Dados de Pesquisa, 2017. 
Na Tabela 3, aqueles que apresentaram “outros” motivos para não utilização das respectivas ferramentas informaram que não as utilizam porque consideram o serviço contábil apenas para atender questões de cunho fiscal, e mesmo conhecendo algumas ferramentas não veem necessidade de utilização.

Tabela 4

Toma decisão com base nas ferramentas que utiliza

\begin{tabular}{ccc}
\hline Sim & Não \\
\hline 30 & 2 & \\
\hline $93,8 \%$ & $6,2 \%$ \\
\hline
\end{tabular}

Fonte: Dados de Pesquisa, 2017.

Não foram apresentadas justificativas pelos respondentes para não utilização das ferramentas e informações gerenciais.

Outros resultados encontrados foi que 12,5\% relataram atrasos na geração e utilização das informações com base nas ferramentas utilizadas, ou pelo menos em algumas delas, porém não se apresentou por nenhum desses os impactos que esse atraso geraria na entidade e no processo decisório sejam eles de natureza financeira ou não. Alguns apresentaram as ferramentas que mais chegam com atraso para utilização: O Balanço Patrimonial e informações de controle de contas a receber. O primeiro de responsabilidade da contabilidade e o segundo de responsabilidade interna da empresa.

Nessa questão específica de "contas a receber", os respondentes consideram seu controle como: eficiente $(15,6 \%)$, relativamente eficiente, havendo sempre valores a receber que estão em atraso (50\%), pouco eficiente, havendo sempre valores a receber em atraso e em alguns casos nem recebidos (18,8\%), ineficiente, uma vez que todas as vendas estão em atraso no que se refere a recebimentos $(12,5 \%)$ e outros $(3,1 \%)$ alegaram que não existem contas a receber em seu estabelecimento, onde o mesmo só efetua transações a vista.

A destinação do lucro, em sua maioria é revertida em novos investimentos para a empresa bem como para aquisição de estoques. Outros responderam que fazem reservas em caixa e em bancos e outros ainda destinam para uso doméstico uma parcela desse lucro.

Com relação a outros aspectos gerenciais tais como se os mesmos pagam algum título em atraso mesmo possuindo reserva de caixa, 96,9\% responderam que não. No que se refere a utilização de recursos da empresa para fins particulares a amostra ficou dividida. 50\% afirmaram que não usam valores ou recursos da empresa para fins pessoais e outros 50\% afirmaram que sim, que utilizavam os respectivos recursos para fins pessoais, onde a destinação é bem diversificada, tais como: alimentação pessoal e familiar, despesas domésticas, imóveis e viagens e gastos com educação dos filhos. Como justificativas para tal prática surgiram respostas do tipo: "é uma empresa familiar, portanto é normal" e "se não usar em casa a família passa necessidade".

A Tabela 5 apresenta os principais fatores impeditivos para implementação e utilização das ferramentas gerenciais pelos micro e pequenos empreendimentos. A frequência de resposta nessa Tabela se deu pela possibilidade de escolha de mais de uma alternativa, não se restringindo somente a amostra de 32 respondentes.

Tabela 5

Principais motivos impeditivos de utilização das informações e ferramentas gerenciais

\begin{tabular}{|c|c|c|c|c|c|c|}
\hline $\begin{array}{c}\text { Desconhece a } \\
\text { utilidade }\end{array}$ & $\begin{array}{c}\text { Falta de } \\
\text { comunicação } \\
\text { com o contador }\end{array}$ & $\begin{array}{l}\text { Dificuldade de } \\
\text { interpretação }\end{array}$ & $\begin{array}{l}\text { Descrédito na } \\
\text { contabilidade }\end{array}$ & $\begin{array}{c}\text { Informação } \\
\text { contábil não } \\
\text { apresenta a realidade }\end{array}$ & $\begin{array}{c}\text { A experiência } \\
\text { resolve os } \\
\text { problemas } \\
\end{array}$ & Outros \\
\hline 7 & 7 & 3 & 1 & 3 & 16 & 4 \\
\hline $17,1 \%$ & 17,1 & $7,3 \%$ & $2,4 \%$ & $7,3 \%$ & $39 \%$ & $9,8 \%$ \\
\hline
\end{tabular}

Fonte: Dados de Pesquisa, 2017. 
Os que responderam "outros", apresentaram as seguintes justificativas: "não entendo de contabilidade e dessas informações", "não utilizo porque não tenho dificuldade alguma nas informações que são geradas e as mesmas já servem" e "a informação contábil disponibilizada retrata a realidade da empresa, não necessitando de outras".

Como último questionamento, o respondente deveria responder se, inexistindo uma norma regulamentar que dispensasse a empresa de utilização da contabilidade, se os mesmos ainda a utilizariam no processo de auxílio a gestão.

Como resultado, se teve que 18,8\% não responderam, e os demais apresentaram respostas diversificadas, sendo que $62,5 \%$ disseram que "sim", utilizariam a contabilidade e suas ferramentas para auxilio no processo de gestão. Os motivos foram diversos, tais como: maior segurança; certeza de se estar fazendo o correto gerenciamento; necessidade, uma vez que possui conhecimentos limitados; "para todos os efeitos se necessita para algum fim"; é importante para a boa gestão financeira; existem particularidades que só alguém capacitado pode resolver; a contabilidade tem papel fundamental; é útil; é importante para o progresso do negócio; é confiável; é um agente que auxilia na desburocratização, etc.

Dos 18,7\% que não utilizariam a contabilidade, caso não fosse obrigado por norma, os motivos também foram diversos: "utiliza, pois é o jeito", "só usa porque é obrigado", "seria uma economia grande", "sabe manusear e gerar tudo que a contabilidade faz" e outros apenas colocaram que não a utilizaria, não apresentando nenhuma justificativa.

De maneira geral se percebe que existe uma significante utilização das ferramentas gerenciais, se conscientes ou não, não é objetivo do trabalho definir, porém o que fica de resultado expressivo é que as decisões nesses estabelecimentos ocorrem muito de maneira intuitiva e com base nas experiências passadas, mesmo sendo considerado que a contabilidade auxilia e é importante no processo de gestão. Ressalte-se que essa importância se da mais pelos aspectos fiscais do que pelos contábeis.

\section{Considerações finais}

Diante desse contexto essa pesquisa objetivou verificar as ferramentas utilizadas pelas MPE e as formas com que as mesmas são utilizadas no gerenciamento e na tomada de decisão, além de identificar quais os principais fatores que impedem a implementação das respectivas ferramentas e sua utilização.

Com relação às informações e ferramentas gerenciais, se tem que a princípio, o próprio dono participa da gestão, a contabilidade é um serviço prestado por profissional externo a entidade de maneira terceirizada.

As ferramentas apresentadas são, em média, de acordo com os respondentes, utilizadas por 53,1\%, sendo que existem as que são mais fortemente utilizadas em detrimento de outras. Importante destacar que as informações puramente contábeis, tais como: Balanço Patrimonial, Demonstração do Resultado, Balancete de Verificação, etc., são as que são menos demandadas e utilizadas, utilizando-se mais de informações de cunho fiscal para o gerenciamento.

A contabilidade só contribui nesse processo quando é demandada. Porém quando corre a solicitação, o nível de satisfação e de utilidade no processo de gerenciamento e tomada de decisão é satisfatório.

Os respondentes afirmam que utilizam as ferramentas no processo decisório, só que, também afirmam que a maioria de suas decisões são baseadas em experiências passadas e de maneira intuitiva.

Por fim, e no que se refere a utilização da contabilidade e de suas informações mesmo dispensados, a maioria, ou $62,5 \%$ afirmaram que a utilizariam por considerarem que a mesma possui elementos que podem 
contribuir no bom gerenciamento do negócio, tendo ferramentas que possibilitam uma maior capacidade de gerenciamento racional e de crescimento.

No que se refere às limitações do estudo, a principal a ser destacada é o pouco interesse dos respondentes em participar da pesquisa, e, mesmo participando, por vezes não respondem aos questionamentos de maneira racional e reflexiva o que pode enviesar e prejudicar as análises dos dados. Outra limitação se dá em função do ambiente de pesquisa, uma vez que se trata apenas de uma microrregião do estado. Portanto, sugere-se para futuras pesquisas ampliar o ambiente, bem como a amostra de modo que se possa ter uma leitura maior do contexto das MPE e também se possa fazer algumas análises comparativas entre regiões.

\section{Referências}

Beuren, I. M. (org). (2012). Como elaborar trabalhos monográficos em contabilidade: teoria e prátrica. 3. ed. 7. reimpr. São Paulo: Atlas.

Beuren, I. M. \& Rengel, S. (2012). Uso dos atributos da contabilidade gerencial propostos por Moores e Yuen (2001) em empresas de um segmento industrial de Santa Catarina. Revista Brasileira de Gestão e Negócios. São Paulo, v. 14, n. 45, p. 453-479, out./dez.

Bomfim, E. T., Teixeira, W. S. \& Callado, A. L. C. A. (2013). Utilização de indicadores de desempenho em micros e pequenas empresas: Um Estudo em Empresas Localizadas em João Pessoa - PB. (Acessed Oct 2016). http://www.desafioonline.com.br/publicaçõesDesafio Online, Campo Grande, v. 1, n. 1, Jan./Abr.

Brasil. Lei Complementar 123 de 14 de dezembro de 2006. Institui o Estatuto Nacional da Micro Empresa e da Empresa de Pequeno Porte. (Acessed Oct 2016). http://www.planalto.gov.br/ccivil_03/leis/LCP/Lcp123.htm.

Brasil. Lei Complementar 128 de 19 de dezembro de 2008. (Acessed Oct 2016). http://www.planalto.gov.br/ ccivil_03/leis/LCP/Lcp128.htm.

Cabral, R. J., Silva, M. K. \& Magalhaes, M. G. (2012). Panorama do papel das micro e pequenas empresas no mercado de trabalho na cidade de Pouso Alegre - MG. IX Simpósio de Excelência em Gestão e Tecnologia.

Callado, A. L. C., Callado, A. A. C. \& Silva, M. C. M. (2011). Caracterizando os sistema de informação gerencial na gestão de custos em micro e pequenas empresas. Rev. Ciênc. Admin., Fortaleza, 17 (2): 351-374, maio/ago.

Carmo, C. R. S., Santos, T. G. \& Lima, I. G. (2013). A utilização de "artefatos de custos" por micro e pequenas empresas (MPEs) da cidade de Uberlândia-MG, Brasil. Revista del Instituto Internacional de Costos, n. 12, p. 5-27. 
Clemente, F. (2007). Pesquisa exploratória e fenomenológica: alguns conceitos básicos. (Acessed Nov 2017). HTTP://www.administradores.com.br/informe-se/artigos/pesquisa-qualitativa-exploratória-fenomenológica-alguns-conceitos-basicos/14316.

Collins, J. \& Hussey, R. (2005). Pesquisa em administração. 2a ed. Porto Alegre: Bookman.

Gerhardt, T. E. \& Silveira, D. T. (org). (2009). Métodos de pesquisa. Universidade Aberta do Brasil (UAB/ UFRGS). Porto Alegre.

Gil, A. C. (1999). Métodos e técnicas de pesquisa social. São Paulo: Atlas. . (2008). Como elaborar projetos de pesquisa. 4. ed. São Paulo: Atlas.

Horngren, C. T. et. al. (2008). Contabilidade gerencial. 14º ed. São Paulo: Prentice Hall.

Ibge - Instituto Brasileiro de Geografia e Estatísticas. Estimativas da População. (2015). (Acessed Oct 2017). http://www.ibge.gov.br/home/estatistica/populacao/estimativa2015/estimativa_dou.shtm. - Instituto Brasileiro de Geografia e Estatísticas. Estimativas da População. (2017). (Acessed Oct 2017). http://www.ibge.gov.br/home/estatistica/populacao/estimativa2017/estimativa_dou.shtm.

Marconi, M. A. \& Lakatos, E. M. (2005). Fundamentos da metodologia científica. $6^{\text {a }}$ ed. São Paulo.

Martins, A. (2014). Utilização das ferramentas da gestão financeira nas empresas: análise das micro e pequenas empresas da cidade de Pato Branco no sudoeste do Paraná. Monografia (Graduação em Ciências contábeis) - Departamento Acadêmico de Ciências Contábeis, Universidade Tecnológica Federal do Paraná, Pato Branco-PR.

Morais, O. O., Coelho, A. C. D. \& Holanda, A. P. (2014). Artefatos de contabilidade gerencial e maximização do valor em firmas brasileiras. Revista de Contabilidade \& Controladoria. UFPR. Curitiba-PR, v. 6, n. 2, p. 128-146, maio/ago.

Moreira, R. L. et al. (2013). A importância da informação contábil no processo de tomada de decisão nas micro e pequenas empresas. Revista Contemporânea de Contabilidade. UFSC. Florianópolis-SC, v. 10, n. 19, p. 119-140.

Moura, M. F., Pereira, N. A. \& Rech, I. (2016). Análise quanto ao uso de ferramentas e informações gerenciais pelos produtores de gado de corte. Revista Evidenciação Contábil \& Finanças, João Pessoa, v. 4, n. 3, p. $72-$ 88, set./dez. 
Panucci Filho, L. \& Almeida, L. B. A. (2011). Contabilidade gerencial no crescimento das organizações: Um estudo nas indústrias de confecções. Revista Iberoamericana de Contabilidad de Gestión, v. 9, n. 18, p. 1-17.

Pianovski, F. R. \& Barella, L. A. (2016). Contabilidade gerencial: um estudo sobre as práticas de gestão em micro e pequenas empresas na cidade de alta floresta - MT. REFAF - Revista eletrônica. Faculdade de Alta Floresta-MT, v. 2, n. 4.

Prakash, M. (20130. Evolution and changes in management accounting practices. International Research Journal of Management Science \& Technology, v. 4, n. 2, p. 1009-1017.

Richardson, R. J. (1999). Pesquisa social: métodos e técnicas. 3. ed. São Paulo: Atlas.

Sales, R. L., Barros, A. A. \& Pereira, C. M. M. A. (2011). Fatores condicionantes da mortalidade dos pequenos negócios em um típico município interiorano brasileiro. Revista da Micro e Pequena Empresa, v. 5, n. 1, p. $38-55$.

Santos, J. V. J. et al. (2017). Análise dos artefatos gerenciais utilizados pelos Food Trucks da cidade de Natal/ RN. Revista de Gestão, Finanças e Contabilidade, v. 7, n.3, p. 105-126, set./dez.

Santos, V., Dorow, D. R. \& Beuren, I. M. (2016). Práticas gerenciais de micro e pequenas empresas. Revista Ambiente Contábil, v. 8, n. 1, jan./jun. ISSN 2176-9036.

Santos, V. et al. (2009). Instrumentos de contabilidade gerencial utilizados em micro e pequenas empresas comerciais e disponibilizados por empresas de serviços contábeis. Revista Catarinense de Ciência Contábil. CRC/SC-Florianópolis-SC, v. 8, n. 24, p. 41-58, ago./nov.

Sebrae - Serviço Brasileiro de Apoio as Micro e Pequenas Empresas. (2015). Participação das Micro e Pequenas Empresas na Economia Brasileira: Relatório Executivo.

Silva, D. J. C. et al. (2010). Para que serve a informação contábil nas micro e pequenas empresas. Revista Contemporânea de Contabilidade. UFSC. Florianópolis-SC, ano 7, v. 1, n. 13, p. 89-106, jan./jun.

Stacke, J. A. \& Feil, A. A. (2017). Análise da utilização das ferramentas contábeis gerenciais em micro e pequenas empresas. Revista Gestão e Desenvolvimento. Novo Hamburgo, v. 14, n. 1, jan./jun.

Teixeira, A. J. C. et al. (2011). Utilização de Ferramentas de Contabilidade Gerencial nas Empresas do Estado do Espírito Santo. BBR Brazilian Business Review. v. 8, n.3Vitória-ES, Jul. - Set. p. 108 - 127 ISSN 1807$734 X$. 